\title{
VISIBILIDAD COMO ESTRATEGIA DE MOVILIDAD: EL ÉXOdO CENTROAMERICANO EN MÉXICO (2018-2019)
}

\author{
Visibility as a Mobility Strategy: the Central \\ American Exodus IN MeXico (2018-2019)
}

\section{María Dolores París Pombo* \\ Verónica Montes ${ }^{\star *}$}

Resumen: A pesar de que desde hace décadas existe una alta movilidad de personas centroamericanas trasladándose por territorio mexicano en busca de llegar a Estados Unidos, no se había observado a grupos tan grandes viajando en contingentes, como sucedió con las llamadas caravanas migrantes durante 2018-2019. Este éxodo tiene características sin precedentes a nivel de la movilidad humana en la región por las formas de organización, el número y la heterogeneidad de las personas que marcharon juntas por México (adolescentes, madres solteras con hijos, menores no acompañados, personas con discapacidades físicas, personas mayores, personas LGTBQ). Este artículo muestra que la visibilidad de las caravanas permitió que miles de centroamericanos llegaran hasta la frontera norte pese a las condiciones de violencia que han caracterizado a la movilidad humana en el país. Sin embargo, la fuerza colectiva se fue perdiendo a medida que los migrantes se

\footnotetext{
* Investigadora en El Colegio de la Frontera Norte, Tijuana. Líneas de investigación: Migraciones y derechos humanos, deportaciones, violencia. Dirección electrónica: mdparis@colef. mx. Dirección postal: Km. 18.5 Escénica Tijuana-Ensenada, San Antonio del Mar, C.P. 22560, Tijuana, Baja California (México).

** Afiliación institucional: Bryn Mawr College, Filadelfia. Líneas de investigación: Comunidades migrantes mexicanas y latinoamericanas en EU; intersecciones entre los procesos de hogar, pertenencia y migración; Latinos en EU; y maternidad transnacional y deportación. Dirección electrónica: vmontes@brynmawr.edu. Dirección postal: 101 N. Merion Ave. Bryn Mawr, PA 19010 (USA). ORCID: https://orcid.org/0000-0002-0702-2048.

Fecha de recepción: 01/09/2019, fecha de aceptación: 18/10/2019.
}

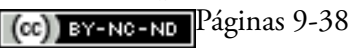


dispersaban a lo largo del camino. Una vez en Tijuana, y en otras ciudades fronterizas, los caravaneros se encontraron con múltiples riesgos y tendieron a volverse nuevamente invisibles.

Palabras clave: Caravanas de migrantes, (in)visibilidad, movilidad humana, violencia, Tijuana.

Abstract: Even though for decades there have been important movements of Central American people through Mexican territory in search of reaching the United States, no such large group had been observed traveling en masse, as was the case with the so-called migrant caravans in 2018-2019. This exodus has unprecedented characteristics in terms of human mobility in the region, concerning the organization, the number and the heterogeneity of people (adolescents, single mothers with children, unaccompanied minors, handicapped, elderly and LGTBQ people). This article shows that the visibility of the caravans was the decisive factor that allowed thousands of Central Americans to reach the border and cope with the violence that has characterized human mobility in Mexico. However, the collective force was lost as migrants dispersed along the road. Once in Tijuana and other border cities, the caravaneros had to face multiple risks individually and tended to become invisible again.

Keywords: Migrant caravans, (In)visibility, Human Mobility, Violence, Tijuana.

\section{Introducción}

Los años 2018 y 2019 serán ciertamente reconocidos en el ámbito de la movilidad humana por las llamadas “caravanas migrantes". Si bien éste no es un fenómeno nuevo en México, sus características cambiaron considerablemente a partir de 2018, hasta transformarse en lo que después fue nombrado como "el éxodo". Hasta entonces, las caravanas eran conocidas por los defensores de migrantes y por estudiosos de la migración como manifestaciones de carácter político y religioso cuyo propósito era denunciar la altísima peligrosidad de las rutas migratorias en este país. Integradas por familiares de migrantes 
asesinados o desaparecidos y por miembros de organizaciones de la sociedad civil dedicadas a la defensa de los migrantes, las caravanas de madres de migrantes desaparecidos y el Viacrucis migrante entraban cada año a territorio mexicano y recorrían algunas ciudades del país realizando encuentros con actores políticos y sociales. Algunos periódicos nacionales daban cuenta de sus avances, de sus reuniones, y a veces revelaban sus logros cuando las madres encontraban a sus hijos con vida.

La caravana migrante adquirió otros significados en octubre de 2018, cuando las redes sociales hondureñas empezaron a convocar a una movilización para huir del país y emigrar a Estados Unidos. Miles de hondureños, pero también de salvadoreños, guatemaltecos e incluso personas de otros países se fueron uniendo al contingente y caminaron por el norte de Centroamérica, forzando la entrada a México por la frontera entre Tecún Umán (Guatemala) y Ciudad Hidalgo (Chiapas). El propósito fundamental de las personas que se unieron en el camino era cumplir con su necesidad o su interés de emigrar al norte. La mayoría huía de situaciones de violencia generalizada y de violaciones masivas a derechos humanos en sus países.

Este fenómeno logró cambiar la representación de la movilidad humana en México. Los medios de comunicación del mundo entero reportaron día con día los avances, no sólo de esa caravana de octubre, sino también de las que le siguieron durante el último trimestre de 2018 y el primero de 2019. De las tradicionales ilustraciones de la migración centroamericana concentradas en el tren de carga, conocido como "la Bestia", los medios pasaron a representarla con imágenes de largas columnas de personas que caminan como un contingente a lo largo de las carreteras del sur de México.

En este artículo mostramos cómo la visibilidad del éxodo centroamericano significó una estrategia para confrontar la violencia contra las personas migrantes y la criminalización de la movilidad humana en México. El éxodo da cuenta de las condiciones de precariedad en las que huyen actualmente miles de familias centroamericanas. Así, en las caravanas que salieron de Honduras y El Salvador durante el último trimestre de 2018 y el primero de 2019, llamaba la atención la presencia de numerosas mujeres empujando carriolas con niñas y niños pequeños, personas con capacidades diferentes, adultos mayores y adolescentes (De Alba, Pernalete y Pastrana, 2018). 
Proponemos entonces, en primer lugar, analizar las estrategias de visibilización de la movilidad humana con vistas a confrontar los altos riesgos que corren los migrantes en México. Estos riesgos han sido construidos por políticas migratorias cada vez más restrictivas y punitivas (París, 2019), así como por la criminalización de la movilidad humana. En un segundo apartado, describimos las masivas violaciones a los derechos humanos por parte de organizaciones criminales, funcionarios públicos, delincuentes comunes e incluso población en general en las rutas migratorias. En tercer lugar, mostramos la importancia que han ido cobrando las luchas por los derechos de los migrantes, en particular la historia de las caravanas migrantes como una manifestación política y religiosa en el marco del movimiento de derechos humanos en México y Centroamérica. A continuación, describimos las características que fueron tomando las caravanas migrantes durante el último trimestre de 2018 y el primero de 2019, subrayando las características de esta nueva forma de movilidad colectiva desde Centroamérica y hasta la frontera México-Estados Unidos. Finalmente, describimos las diversas motivaciones de los caravaneros, sus expectativas y proyectos migratorios, que fueron construyéndose a veces en la coyuntura de las caravanas y en las necesidades de huida.

Presentamos aquí algunos resultados de diversas etapas y experiencias de investigación participativa en el marco de la movilidad humana y de la defensa de derechos humanos. La primera autora recupera un trabajo de indagación sobre las raíces de la violencia contra las personas migrantes y el papel de las políticas migratorias en la criminalización de la migración indocumentada en México (París, 2017 y 2019). Asimismo, utilizamos algunos hallazgos del trabajo de campo que realizó como parte de un amplio equipo de investigación formado en El Colegio de la Frontera Norte, y que llevó a cabo varias visitas a los lugares de alojamiento de los caravaneros en Tijuana y dos encuestas, aplicadas a una totalidad de casi 2,000 migrantes integrantes de las caravanas del último trimestre de 2018. La segunda autora recupera su acompańamiento y observación participante con algunas personas de la primera caravana migrante, tanto en la Ciudad de México como en Tijuana. Ambas autoras dieron seguimiento, durante 2019, al proceso de llegada e instalación de las caravanas migrantes a través de visitas a los lugares de alojamiento o 
de asentamiento en Tijuana y por medio de entrevistas a profundidad con integrantes de las caravanas y líderes que se quedaron en esta ciudad.

\section{Estrategia de (in)visibilidad del éxodo centroamericano}

En 2010, Amnistía Internacional (AI) publicó un informe titulado "Víctimas Invisibles" (Amnistía Internacional, 2010), que reportaba las violaciones masivas a los derechos humanos de los migrantes en México. Describía, por un lado, las agresiones y delitos de los que eran objeto los migrantes centroamericanos en su paso por este país y, por otro, los abusos cometidos por las autoridades migratorias y policiacas, tales como la fuerza excesiva y la extorsión. Señalaba la falta de datos, tanto sobre el número de migrantes que pasaban realmente por México, como sobre las violaciones a sus derechos humanos. Esta falta de datos, de acuerdo con la organización, estaba relacionada con la clandestinidad a la que se veían obligados los migrantes, la falta de denuncias de los delitos y, en general, con su invisibilidad. Paradójicamente, para ilustrar su portada, Amnistía Internacional usaba una fotografía del tren de carga conocido como "La Bestia", es decir de la cara más visible de la migración centroamericana en México.

Varios otros informes sobre los derechos humanos de los migrantes muestran el tren de carga como la imagen por antonomasia de la movilidad en México. Los artículos periodísticos, los documentales, las películas, los libros y los informes sobre la migración centroamericana en México eran sistemáticamente ilustrados, hasta 2018, por migrantes montados en los techos de los vagones y las juntas de la denominada "Bestia".

Si el tren se asocia con la migración en tránsito es por su espectacularidad: se trata en efecto de una movilidad colectiva - en algunos momentos masiva de decenas o cientos de personas en un solo medio de transporte. Sin embargo, la gran mayoría de los migrantes centroamericanos se transportan por medios mucho menos visibles. Se trata de un movimiento en pequeños grupos, a veces acompañados de un intermediario, guía o "coyote", que avanzan tramos a pie, en camiones, cajas de tráileres, carros privados y autobuses.

Las personas migrantes intentan no ser detectadas ni reconocidas como tales por las autoridades ni por la población mexicana. La mayoría busca llegar hasta Estados Unidos y considera a México únicamente como un territorio de tránsito. Ahora bien, este tránsito puede durar semanas, meses o años, según 
los recursos de que dispongan los migrantes, los riesgos que confrontan y las propias circunstancias del viaje. Durante esos periodos, considerados como de "tránsito", los migrantes se encuentran en un estado de liminalidad (Bibler Coutin, 2005 y Vogd, 2013). Ocupan espacios intersticiales que pertenecen y a la vez están ausentes de la jurisdicción del Estado. Como lo señala Bibler Coutin, "esta migración oculta es simultáneamente una faceta visible de los paisajes sociales" (2005:198).

La naturaleza irregular de la movilidad por México obliga a los migrantes a tomar rutas secundarias, escondidas al público en general; paradójicamente, estas rutas son ampliamente conocidas tanto por las organizaciones sociales que buscan brindar ayuda y protección en el camino, como por las autoridades que ubican regularmente puntos móviles de control para detectar y detener a los migrantes, y por los delincuentes que lucran a través del robo, el asalto y la extorsión sistemática de personas consideradas como "indocumentadas".

$\mathrm{La}$ invisibilidad de los migrantes les permite viajar hacia el norte eludiendo obstáculos interpuestos por políticas migratorias restrictivas y punitivas. Constituye también una estrategia para evitar la discriminación, el abuso, la extorsión y la explotación (Rojas-Wiesner y DeVargas, 2019). La clandestinidad propicia, sin embargo, numerosos riesgos relacionados con la delincuencia y la corrupción. Es decir, al tiempo que permite evitar la detención y la deportación, aumenta también los riesgos que corren los migrantes de ser víctimas de violencia y abusos a manos de delincuentes comunes y de las propias autoridades. Asimismo, esta invisibilidad garantiza la impunidad en el caso de crímenes, delitos y violaciones a sus derechos humanos. Por lo tanto, si bien la invisibilidad es una estrategia de supervivencia, e incluso una forma de resistencia, puede ser también un obstáculo para la agencia social y el reconocimiento de los migrantes como sujetos de derechos (ibídem).

\section{Movilidad humana y derechos humanos en México}

En agosto de 2010, la masacre de 72 migrantes en un rancho del municipio de San Fernando (Tamaulipas) pareció sacudir las conciencias de la clase política y de la sociedad civil mexicana e internacional. Salía a la luz la punta de un iceberg en materia de derechos humanos en México: la violencia generalizada contra las personas migrantes. Desde la toma de posesión del expresidente Felipe Calderón Hinojosa (2006-2012), las noticias revelaban un país en 
guerra, con permanentes confrontaciones armadas, miles de desapariciones forzadas y de homicidios dolosos, fosas comunes y masacres. Pero en estas noticias raramente aparecían los migrantes; retomando de nuevo los términos de Amnistía Internacional (AI, 2010), las personas migrantes constituían "víctimas invisibles".

El espectáculo de la violencia exhibido después de la masacre provocó la visibilidad súbita de la tragedia migratoria, en contraste con el silencio y la invisibilidad de la migración centroamericana en México. Como lo señaló Bibler Coutin (2005), después de transitar sin nombre ni identidad, los migrantes pueden cobrar corporeidad, nacionalidad y nombre propio a través de la muerte, es decir, después de ser asesinados o masacrados. Los familiares de migrantes desaparecidos emprenden la búsqueda por las rutas, los cementerios, las fosas comunes. Algunos se organizan, hacen alianzas con organismos de la sociedad civil y con instituciones gubernamentales y logran, a través de su constancia y de su movilización, recuperar los restos e identificar a sus familiares.

Así, dos semanas después de la masacre de San Fernando, en agosto de $2010^{1}$, se dio a conocer el nombre de Misael Castro Bardales, cuyos restos habían sido repatriados bajo una identidad equivocada pero fue reconocido por su hermana gracias a sus tatuajes (Periodistas de Pie Org., 2014). Otros cuerpos fueron identificados mucho después a través de bancos de ADN, como el de Eva Noemí, quien fue identificada gracias al convenio de colaboración entre la Procuraduría General de la República (PGR), la Fundación para la Justicia y el Equipo Argentino de Antropología Forense (EAAF); sus restos fueron repatriados a Honduras en julio de 2014, casi cuatro años después de la masacre.

La crisis humanitaria que vive México en materia de movilidad humana empezó a ser difundida al menos desde 2007 (París, 2017), primero a través de declaraciones de defensores y de artículos periodísticos, después a través de informes de la sociedad civil y de la Comisión Nacional de los Derechos Humanos (CNDH, 2009). El Relator Especial de la Organización de las Naciones Unidas (ONU) sobre los Derechos Humanos de los Migrantes, Jorge Bustamante, emitió un informe en 2008 donde ponía en evidencia la participación de autoridades, delincuentes comunes y organizaciones

\footnotetext{
${ }^{1}$ Esta no fue la única masacre en ese municipio. El año siguiente, fueron descubiertas 47 fosas comunes con 193 cuerpos también en San Fernando.
} 
criminales en las cadenas de violencia contra los migrantes. Estas comprendían el robo, el asalto, la extorsión, los delitos sexuales, el enganche forzado de jóvenes migrantes para el crimen organizado, el secuestro sistemático y masivo a cambio del pago de rescate y el secuestro de mujeres, niñas, niños y adolescentes migrantes para la trata con fines de explotación sexual y laboral (Bustamante, 2008). Sin embargo, las autoridades mexicanas y la comunidad internacional acogieron dichos informes con pocas reacciones políticas y casi ninguna acción pública.

En cambio, la primera masacre de San Fernando precipitó varios procesos políticos en materia de movilidad humana. En primer lugar, con el apoyo de varias organizaciones de la sociedad civil y por unanimidad, el Congreso de la Unión aprobó, en 2011, una Ley de Migración que reconoce que las personas migrantes gozarán de todos los derechos humanos sin importar su condición migratoria. En 2013, el gobierno mexicano promovió varios foros de discusión y se formó una alianza importante entre organismos de la sociedad civil para diseñar y promover el Programa Especial de Migración 2014-2018, que priorizaba casi en cada capítulo la temática de los derechos humanos ${ }^{2}$.

Sin embargo, la mayor parte de estos avances quedaron en letra muerta; las condiciones de violencia contra los migrantes han continuado prevaleciendo hasta la actualidad, como lo muestran los informes más recientes de la sociedad civil (Red de Documentación de Organizaciones Defensoras de Migrantes, 2018; Colectivo de Observación y Monitoreo de Derechos Humanos en el Sureste Mexicano, 2019). Esta violencia comprende no sólo las agresiones de las redes criminales que lucran con el tráfico y la trata de personas, o los delincuentes comunes que acosan a los migrantes a lo largo de las rutas principales, sino también la violencia institucional ejercida cotidianamente por los cuerpos de seguridad ${ }^{3}$. En relación con el cúmulo de delitos y violaciones a derechos humanos de los migrantes, ha prevalecido la impunidad. Esta

\footnotetext{
${ }^{2}$ La redacción de este programa se logró gracias a una participación sin precedentes de la sociedad civil organizada y de la academia en foros nacionales e internacionales de consulta, y a través de llamado "Colectivo PND-Migración". Esta agrupación buscó incidir en el Plan Nacional de Desarrollo 2013-2018 y logró colocar el tema de migración en la agenda de varias de las instituciones públicas (Wolf, 2014).

${ }^{3}$ En junio 2019, el gobierno de Andrés Manuel López Obrador desplegó enormes operativos contra los migrantes a través de un nuevo cuerpo de seguridad, la Guardia Nacional, que se integró con agentes de la Marina, del Ejército y de la Policía Federal.
} 
impunidad sistemática ante actos de lesa humanidad sólo puede explicarse por la aceptación tácita o expresa de que las muertes de migrantes son necesarias, representan un sufrimiento social ejemplar para disuadir la futura migración (París, 2017).

Como lo señala Linda Green (2011:367), la extrema vulnerabilidad de los migrantes deriva, en primer lugar, de factores geopolíticos y de doctrinas económicas que producen no-personas (nobodies) en el sur global, así como empleos peligrosos, mal pagados y no sindicalizados en los países más desarrollados. En segundo lugar, la vulnerabilidad es producto de la falta de alternativas económicas en grandes estratos de la población. Es consecuencia, en tercer lugar, de leyes punitivas y de prácticas políticas que han configurado las fronteras en zonas militarizadas o de seguridad nacional.

Presionado por el gobierno de Estados Unidos para frenar el flujo migratorio, el Estado mexicano ha aplicado desde hace más de 25 años una política de contención migratoria que hace caso omiso de las garantías personales. Es en este tenor que, desde la creación del Instituto Nacional de Migración (INM) en 1993, el gobierno mexicano ha invertido en la construcción de una amplia infraestructura de detención que comprende 59 centros de detención para personas migrantes: 32 estaciones migratorias, 15 estancias provisionales tipo A para una estancia máxima de 48 horas y 12 estancias provisionales de tipo B para una estadía máxima de 7 días (Consejo Ciudadano del Instituto Nacional de Migración, 2017: 43).

La detección y detención de migrantes en todo el territorio nacional se lleva a cabo, principalmente, a través de puntos móviles de control y retenes permanentes en las carreteras y en las vías del tren. Estos puntos de control son operados por el INM con participación de la policía federal (París, 2019). Sin embargo, este amplio sistema de detención y deportación funciona también como un filtro, es decir, muchas de las personas transitan a través de los retenes y de los puntos de control pagando sobornos a policías y agentes de migración. A pesar de que actualmente (durante el verano 2019), las personas migrantes son detenidas en las estaciones migratorias en condiciones de hacinamiento, en algunas de ellas hay más de 100\% por encima de la capacidad de detención, cientos de miles de migrantes centroamericanos logran llegar hasta la frontera con Estados Unidos ${ }^{4}$.

\footnotetext{
${ }^{4}$ Esto se puede deducir por el número muy elevado de migrantes centroamericanos detenidos por la Patrulla Fronteriza de Estados Unidos. Por ejemplo, entre marzo y mayo 2019, más de 


\section{Movilizaciones de resistencia contra la violencia hacia los migrantes}

Ante las violaciones graves y permanentes contra los derechos de las personas migrantes en México, se han ido fundando, al menos desde fines de la década de 1980, decenas de albergues, casas del migrante, comedores y organizaciones de defensa de los migrantes en las regiones fronterizas y en las principales rutas migratorias. Estas organizaciones reciben y protegen a los migrantes a lo largo de las rutas clandestinas, particularmente en las cercanías del ferrocarril. Algunas participan en redes que llevan a cabo un monitoreo permanente de las condiciones de peligrosidad y que emiten regularmente informes sobre la violencia que viven los migrantes 5 .

Un movimiento importante de resistencia ha sido el de los comités de familiares de personas centroamericanas desaparecidas en la ruta migratoria. Dando continuidad a la lucha contra la práctica de la desaparición forzada, que emergió como una forma extrema de violencia estatal durante las dictaduras de las décadas de 1960, 1970 y 1980, el movimiento de madres y familiares de migrantes desaparecidos empezó a organizarse en comités desde el principio del siglo XXI. El primero en nacer fue el Comité de Familiares de Migrantes Desaparecidos de El Progreso, Honduras (COFAMIPRO), en septiembre de 1999, gracias a las comunicaciones en el programa radiofónico "Sin Fronteras" (hoy "Abriendo Fronteras") que se transmitía por Radio Progreso. Este programa recibía regularmente llamadas de madres que buscaban a sus hijos, que habían dejado de comunicarse después de emprender la ruta migratoria hacia el norte (COFAMIPRO, 2019). En 2006, surgió el Comité de Familiares de Migrantes Fallecidos y Desaparecidos de El Salvador (COFAMIDE).

Hace 14 años, estos comités y otras asociaciones de madres y familiares de migrantes empezaron a recorrer México en las llamadas "caravanas de madres". Esta movilización fue auspiciada también por una organización mexicana denominada Movimiento Migrante Mesoamericano. Durante el último

100 mil personas cada mes lograron cruzar México e intentaron ingresar a Estados Unidos de manera irregular, siendo detenidas cerca de la frontera por la Patrulla Fronteriza. Oficina de Aduanas y Protección Fronterizas (CBP por sus siglas en inglés) (Oficina de Aduanas y Protección Fronterizas, 2019).

${ }^{5}$ Destaca en cuestiones de monitoreo la Red de Documentación de Organizaciones Defensoras de Migrantes (REDODEM), que emite cada año un informe a nivel nacional. Esta Red integra a casas del migrante, albergues y organismos de derechos humanos de todo el país. 
trimestre de cada año, la caravana de madres sale de la frontera entre Guatemala y México y se detiene en una docena de ciudades en territorio mexicano para realizar encuentros con la sociedad civil organizada (Movimiento Migrante Mesoamericano, 2018). En búsqueda de los migrantes desaparecidos, esta caravana recorre las vías del tren de carga, las cárceles mexicanas, las zonas de bares y prostitución, las estaciones migratorias, los hospitales y las morgues. Las madres también visitan las oficinas de instituciones mexicanas como el INM, la SEGOb, el Senado o la Cámara de Diputados (Varela, 2012). En este recorrido, son acompañadas y recibidas por organizaciones y movimientos de solidaridad.

Otra manifestación de protesta y resistencia contra las violaciones a los derechos de los migrantes en México que ha tomado el nombre de "caravana" ha sido el Viacrucis migrante. Éste es organizado en fechas cercanas a la Semana Santa. Los primeros Viacrucis recibían el apoyo de la la Iglesia Católica a través de la dimensión pastoral de la movilidad humana, de algunas casas del migrante, y de organizaciones de derechos humanos y de defensa de los migrantes de Centroamérica y de México. La narrativa católica y el apoyo de la iglesia brindaba una autoridad moral importante a los defensores y a los propios migrantes. Estos recorrían las rutas principales de tránsito, oficiaban misas, realizaban actos de protesta y de denuncia a lo largo del camino. Generalmente esta movilización terminaba en la Ciudad de México o en alguna ciudad del norte del país (París, 2017).

A partir de 2015, la mayoría de los albergues, de las organizaciones y redes de derechos humanos se distanciaron de estas caravanas debido a diferencias sobre los objetivos y la logística. Cada vez más, el Viacrucis dejó de ser una representación de carácter religioso-político, para volverse un reclamo por el derecho a la movilidad. Migrantes y solicitantes de asilo se unían así a este movimiento con la finalidad de viajar hasta la frontera norte de México al amparo de organizaciones políticas que venían escoltándolos, para intentar después ingresar a Estados Unidos. Un problema cada vez más agudo fue el número muy elevado de migrantes que se unían a las caravanas y la dificultad de darles atención digna a través de las redes de albergues. Fundamentalmente, las caravanas dejaban de ser un modo de protesta y reclamo por los derechos de las personas migrantes para convertirse en un medio de tránsito hacia la frontera norte. Allí, los caravaneros se dispersaban y se veían obligados a 
confrontarse solos con los enormes dispositivos de seguridad en la frontera estadounidense.

En abril 2018, el Viacrucis migrante adquirió por primera vez dimensiones políticas internacionales cuando el presidente estadounidense Donald Trump alertó a través de su twitter sobre "las caravanas" con "olas de migrantes que entraban a México" para llegar Estados Unidos. En todos los medios de comunicación nacionales e internacionales se difundieron cotidianamente los avances de la llamada caravana. Las abundantes noticias provocaron o acentuaron la polarización política del público mexicano y estadounidense en torno a la migración: por un lado, generaron una ola de solidaridad de parte de las comunidades migrantes y defensores de derechos humanos; por el otro, suscitaron miedos y reacciones extremas de xenofobia que raramente se habían visto en México. La difusión de las imágenes de la caravana provocó su propio crecimiento. Es decir, las personas migrantes que, por sus medios o a través de sus redes personales, viajaban hacia el norte de México, fueron sumándose al grupo para encontrar mayor apoyo, solidaridad, protección contra las autoridades policiacas y migratorias y contra la delincuencia.

En octubre de 2018, en las redes sociales hondureñas, se empezó a convocar a una caravana migrante que no coincidía con el Viacrucis, ni tampoco reunía específicamente a las madres de migrantes desaparecidos. La "caravana" dejó de ser una manifestación político-religiosa para transformarse en un medio de movilidad por México que parecía crecer como una bola de nieve. A partir de entonces, esta forma de movilidad adquirió también sentidos políticos extremadamente contrapuestos: para unos, representaba la manipulación de miles de personas de parte de traficantes y activistas con muy pocos escrúpulos, cuyos propósitos eran enriquecerse y desestabilizar al gobierno mexicano o invadir los Estados Unidos. Para otros, se trataba de un éxodo provocado por las condiciones socioeconómicas y políticas, y sobre todo por la violencia generalizada e inseguridad en la región centroamericana.

\section{Las caravanas de 2018}

Durante el último trimestre de 2018, recorrieron el país cuatro movimientos

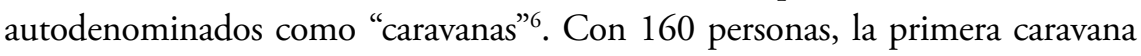

${ }^{6}$ Es importante señalar que la mayoría de los defensores de derechos humanos y varios académicos dejaron de referirse a estos movimientos como "caravanas" y empezaron denominándolo "el éxodo". 
partió de San Pedro Sula, ciudad industrial al norte de Honduras, el 12 de octubre. El número de gente que se fue adhiriendo a la caravana fue creciendo a medida que iban avanzando en su recorrido. Antes incluso de salir de Honduras, la noticia de esta caravana había dado la vuelta al mundo a través de los medios de comunicación y de las redes sociales, así que, al momento de llegar a Ocotepeque, el departamento en Honduras limítrofe con Guatemala y El Salvador, la movilización ya contaba con aproximadamente 2,000 personas.

Cinco días después, cerca de 4,000 personas se habían unido a la caravana y habían logrado llegar a la frontera entre México y Guatemala. Ahí, confrontaron un operativo brutal de contención de parte de la Policía Federal, que lanzó bombas lacrimógenas a las familias hacinadas en el puente internacional y provocó la muerte de una nińa y decenas de personas heridas (el Colef, 2018).

A pesar de la represión, la caravana siguió adelante por territorio mexicano, recorriendo primero el Soconusco y después cruzando el Istmo de Tehuantepec, hasta llegar a Veracruz. A su paso, centenares de migrantes que se encontraban en el camino, y que habían iniciado el viaje hacia el norte por su cuenta o con coyotes, se sumaron al contingente. Muchos hondureños que vieron desde su lugar de origen la evolución de este movimiento masivo de población que avanzaba lentamente hacia el norte, decidieron también emprender el camino y juntarse a la caravana.

Los números de integrantes de estas tres caravanas, de acuerdo con los medios de comunicación, variaban continuamente a medida que éstas avanzaban por territorio mexicano. La razón de estas variaciones no fueron sólo las diferentes formas de estimar el número de personas y la alta dispersión que adquirió la caminata desde Oaxaca. También se debe considerar que muchos de los caravaneros intentaban "alcanzar" al grupo principal en distintos puntos del recorrido; y algunos lo lograban. Otros caravaneros exhaustos, heridos o enfermos, iban abandonando la caminata. La dispersión propició también que algunos grupos aislados fueran detenidos y deportados por el INM. Varios fueron también víctimas de delincuentes comunes o del crimen organizado. Así lo narra Emilio, un líder hondureño integrante de la organización Pueblos Sin Fronteras:

En una vuelta que está saliendo de Tapachula así, para ya agarrar así, para la carretera, ahí nos estaban esperando... nos estaban esperando para matarnos con 
machete. Agarraron a unos compañeros de nosotros y le pusieron el machete en el pescuezo y le quitaron los megáfonos, porque traíamos megáfonos para venir coordinando la gente.

Cuando llegamos así, el compa este que tenían agarrado ellos ahí, le rompieron todos los chalecos a los que nos iban ayudando, con machete se los tiraron así, los megáfonos se los quitaron y cuando nosotros vamos ya a llegar a la vuelta, como que el muchacho, el otro compañero de nosotros, que nosotros le decimos Magaya, llegó donde nosotros todo asustado y toda desgarrada la camisa y nos dijo que no que siguiéramos, que no siguiéramos porque nos estaban esperando para matarnos, y pues, lo que hicimos fue que paramos el grupo de gente que venía atrás de nosotros (Entrevista a Emilio, 2019).

Cuando la caravana llegó a la Ciudad de México, veintitrés días después de haber empezado su recorrido y habiendo avanzado 1,591 kilómetros, se estimó que unas 6,000 personas se habían unido a ella (el Colef, 2018).

La estancia en la CDMX fue la más prolongada y fue ahí donde los caravaneros decidieron la ruta que seguirían rumbo a la frontera norte. Durante esta estancia se pudo realizar el primer censo de la caravana: de las 4,814 personas que la conformaban, 3,088 eran adultas, incluidas 184 personas con discapacidad, 87 eran miembros de la comunidad LGBTQ, 320 niños entre 0 y 5 años, 24 mujeres embarazadas y varios menores de edad no acompańados. Del total, 85\% fueron de Honduras, 8\% de Guatemala, 5\% de Nicaragua, y el $2 \%$ de otros países (ibídem). El viernes 8 de noviembre, los primeros caravaneros empezaron a dejar el estadio Jesús Martínez "Palillo" para continuar su viaje rumbo a la frontera norte por la ruta del Pacífico para llegar a la ciudad fronteriza de Tijuana (ibídem).

Este largo recorrido de 2,771 kilómetros se llevó a cabo en menos de una semana gracias a una estrategia de varios gobiernos estatales que facilitaron recursos para autobuses con tal de conducir a los caravaneros fuera de su estado con la mayor prontitud posible. Así, fueron pocas y cortas las escalas que llevaron a cabo las tres primeras caravanas.

El 11 de noviembre los primeros caravaneros empezaron a llegar a Tijuana. A medida que los días pasaban, los centroamericanos seguían llegando en grupos pequeños y grandes. A diferencia de la CDMX y otros estados, el gobierno municipal de la ciudad de Tijuana no se preparó para el arribo de los 
migrantes, aunque sabían de su llegada. No fue sino hasta el 15 de noviembre que el gobierno municipal de Tijuana autorizó el Centro Deportivo Benito Juárez en la región norte de la ciudad como refugio temporal para los aproximadamente 6,000 centroamericanos que llegaron a Tijuana (ibídem).

Durante la última semana de noviembre y la primera de diciembre, llegaron a Tijuana la mayoría de los integrantes de la segunda caravana migrante, integrada casi totalmente por hondureños, y de la cuarta, que había salido de San Salvador al final del mes de octubre. Fue también en esas semanas cuando, aproximadamente, 2,200 personas fueron trasladadas de la Unidad Deportiva Benito Juárez a un centro denominado el Barretal, ubicado a más de $20 \mathrm{~km}$. al este de la ciudad. Se estimó que alrededor de 1,000 personas en lugar de mudarse al Barretal optaron por irse a uno de los dieciséis albergues para migrantes que existen en Tijuana, mientras que unas 800 personas decidieron quedarse acampando fuera del Benito Juárez, a pesar de que la ciudad no les proporcionó agua potable, baños portátiles, ni luz. Días más tarde, este campamento fue nombrado por los propios migrantes como el espacio Contra Viento y Marea. Por otra parte, un reporte actualizado de el Colegio de la Frontera Norte (el Colef, 2019a) estimó que, para el 7 de diciembre, alrededor de 1,000 personas habían regresado voluntariamente o habían sido repatriadas a sus países de origen. Se estimó también que se desconocía el paradero de alrededor de 1,300 caravaneros, quienes podrían haber rentado algún tipo de vivienda, ya sea en las cuarterías aledañas al Benito Juárez o en otros lugares, como en Playas de Tijuana. ${ }^{7}$

En el informe antes mencionado, el Colef discutió cinco posibles escenarios para los centroamericanos que para ese entonces aún se encontraban en Tijuana: (1) buscar asilo en los EE. UU., (2) solicitar el estatus de refugiado en México, (3) quedarse en Tijuana y buscar un trabajo, (4) repatriación voluntaria o forzada a sus países de origen, y (5) intentar cruzar la frontera ya sea solos o con ayuda de algún coyote (el Colef, 2018). A esta lista añadimos un sexto escenario, que consistió en que los migrantes se trasladaron a otra ciudad fronteriza entre México y Estados Unidos, ya sea con esperanzas laborales o en su búsqueda de cruzar la frontera, se había corrido el rumor que

\footnotetext{
${ }^{7}$ Lorena y Victor, por ejemplo, habían rentado un pequeño cuarto en una de estas llamadas cuarterías que se encontraba a solo un par de calles del Benito Juárez. Lorena nos comentó que otras familias centroamericanas habían rentado una vivienda con ayuda económica de donantes de EU.
} 
en otras ciudades la posibilidad de hacer la solicitud de asilo era más fácil que en Tijuana.

\section{La caravana de enero 2019}

Bajo la consigna "Buscamos refugio, en Honduras nos matan", en la noche del 14 de enero de 2019, el primer grupo, unos 500 participantes, de la nueva caravana salió de San Pedro Sula. Según un informe publicado por el Colef en marzo de 2019, la motivación de esta nueva caravana fue el anuncio emitido el 17 de octubre de 2018 por parte del entonces presidente electo de México, Andrés Manuel López Obrador, en donde se habló sobre el otorgamiento de Tarjetas de Visitantes por Razones Humanitarias (TVRH) a los migrantes (el Colef, 2019b). En nuestra opinión creemos que el factor de atracción en esta ocasión no fue solo la provisión de este tipo de visas, sino también la ubicua cobertura periodística que hicieron de la caravana tanto medios nacionales como internacionales, junto con la serie de falsas, exageradas e incendiarias declaraciones que el presidente Donald Trump empezó a hacer con respecto a las caravanas mucho antes que estas empezaran a ocurrir. La suma de estos factores fue lo que puso a la caravana en la mira pública de miles de centroamericanos que la vieron como una estrategia de movilidad para escapar de sus países.

A diferencia del año 2018, para estas nuevas caravanas el tránsito por México y su arribo a la frontera con EU fueron muy distintos. La Tabla 1 describe suscintamente las principales áreas de diferencia entre las caravanas. Una de las principales diferencias fue la falta de acompañamiento por parte de la sociedad civil organizada y el fuerte control del movimiento de la caravana de parte de las autoridades. Las poblaciones de los pueblos del Soconusco (Chiapas) y del Istmo de Tehuantepec (Oaxaca) que habían recibido a las primeras caravanas con un despliegue importante de solidaridad, mostraron hacia esta nueva caravana cansancio, indiferencia e incluso rechazo.

De acuerdo al testimonio de Emilio, migrante hondureño e integrante de Pueblos Sin Fronteras, quien acompañó también a esta nueva caravana:

Esa caravana fue la más sufrida en todos los aspectos. No les daban nada, absolutamente nada, ni agua. Era raro y contado en los pueblos de ahí de Tapachula hasta Oaxaca que le daban una botella de agua a un migrante... y los 


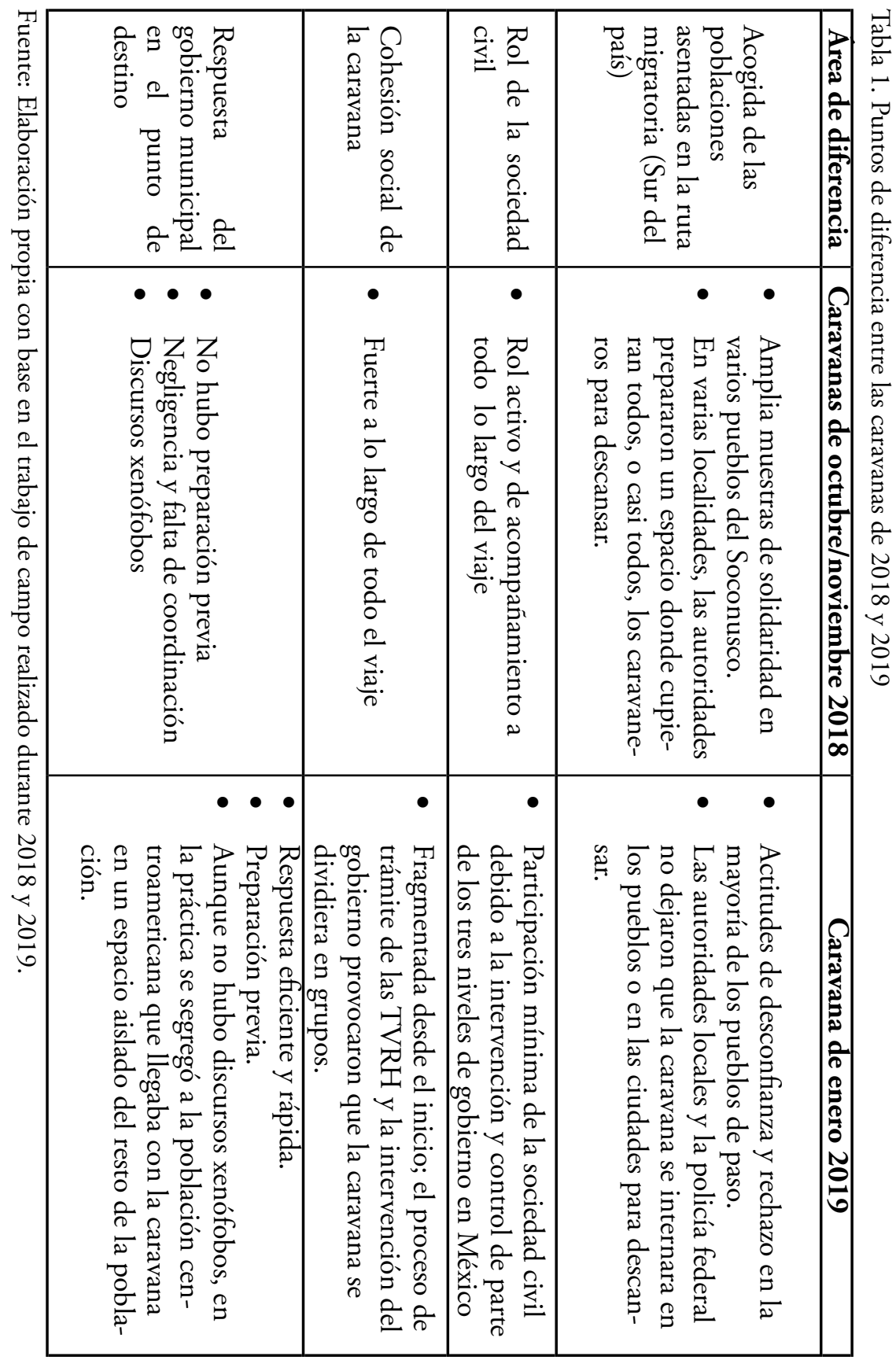


policías, si agarrábamos un aventón a un kilómetro adelante "ipárate!, se baja todo el mundo, a caminar, a caminar hijos de la ...", y que íbamos caminando todos y no nos agüitábamos pues, seguíamos caminando (Entrevista a Emilio, 2019).

Otra característica, diferente de las anteriores, fue que las personas integrantes de la caravana fueron documentadas casi todas en el sur del país a través de las tarjetas de visitante por razones humanitarias (TVRH). En Querétaro, la caravana se dividió en dos y el grupo más numeroso se dirigió hacia la ciudad fronteriza de Piedras Negras (Coahuila). Se trata de una ciudad mucho más pequeña que Tijuana y con pocas posibilidades de integración laboral o cultural de la población centroamericana.

Al llegar a Piedras Negras, el gobierno municipal había habilitado instalaciones muy amplias en un gran almacén para recibir aproximadamente 1,850 personas. Las instalaciones tenían agua fría y caliente, 50 bańos y 40 duchas, agua potable, internet inalámbrico, aire acondicionado, iluminación y pantallas gigantes para el entretenimiento (El Colef, 2019b). A diferencia de la llegada a Tijuana, donde no existió ninguna preparación y se generó un caos que expuso a los caravaneros a actitudes xenofóbicas de parte de la población local, llama la atención la preparación coordinada previa al arribo de los caravaneros a Piedras Negras.

Otra importante diferencia fue la participación y el contacto con los caravaneros por parte de la sociedad civil en cada uno de los lugares de tránsito por los que pasó la caravana. En 2018, la sociedad civil fue la que se encargó principalmente, en el caso de Chiapas, por ejemplo, de recibir y apoyar con comida a los caravaneros. Hubo un contacto directo con la sociedad. Sin embargo, en el caso de las caravanas del 2019 la participación de la sociedad civil no existió, ya que el gobierno federal, junto con los gobiernos estatales por donde cruzaron las caravanas, tuvo el control logístico en todo momento. En este sentido, la visibilidad de las caravanas de 2018, que precisamente fue uno de los factores distintivos de este tipo de movilidad, dejó de estar presente para las caravanas del 2019, lo cual llevó a que fueran perdiendo precisamente su cohesión y fuerza de negociación. 


\section{Diversidad de los integrantes, de sus proyectos migratorios y sus expectativas}

Los participantes en las caravanas de octubre y noviembre de 2018 lograron llegar, en su gran mayoría, hasta la frontera noroeste de México. Sus proyectos eran muy diversos: mientras algunos querían pedir asilo en Estados Unidos, otros simplemente huían de su país y estaban conformes con vivir en algún lugar de México. La heterogeneidad de los caravaneros atañe también a los recursos sociales de los que disponían y a sus experiencias migratorias previas, es decir a la información, conocimientos, contactos y capacidad de movilización. En todos los casos, la llegada a Tijuana (Baja California) representó un reto mayúsculo, pues los obligó a confrontar individualmente los riesgos migratorios y los procesos de criminalización en México y en Estados Unidos.

En este apartado, mostramos cómo las estrategias colectivas de movilidad llevaron a los caravaneros hasta Tijuana. Analizamos los procesos de dispersión y las distintas capacidades para movilizar recursos de parte de los caravaneros. Para ello, narramos las historias de Lorena y Víctor, una pareja hondureńa que se juntó a la primera caravana desde su inicio y decidió seguir con ella hasta Tijuana. Ambos huían de la falta de oportunidades en su lugar de origen, de la inseguridad, la extorsión y la pobreza. Si bien la ruta migratoria representó para ellos un enorme esfuerzo físico, las dificultades y los peligros fueron mucho mayores una vez llegados a la frontera norte de México y sin la protección del colectivo.

Narramos también brevemente la historia de Douglas, quien, a diferencia de Lorena y Víctor, disponía de información amplia sobre sus opciones al llegar a la frontera y había migrado a Estados Unidos previamente. Su capacidad de liderazgo le permitió establecer contactos clave con organizaciones sociales, artistas, intelectuales y abogados, tanto en México como en Estados Unidos. Douglas tenía el proyecto claro de pedir asilo en Estados Unidos; en septiembre 2019 cumplió finalmente con ese objetivo.

\section{Lorena y Víctor}

Víctor, de 49 ańos, y su pareja Lorena, de 48, se unieron a la primera caravana en San Pedro Sula el 13 de octubre 2018. Ambos son de Progreso, Honduras. Antes de unirse a la caravana Víctor trabajó como taxista, sin embargo, la 
extorsión por parte de las pandillas había escalado a tal grado que prácticamente trabajaba solo para ellos. Por su parte, Lorena no tenía un empleo estable y, cuando lograba encontrar algo, se ocupaba en el área de servicios. Víctor comentó que en Honduras es "prácticamente imposible" conseguir trabajo si uno tiene más de 35 años. Lorena por su parte dijo que le sorprendía ver que en México la gente mayor pudiera tener un puesto ambulante y ganarse la vida, ya que en Honduras eso es inimaginable; también comentó que las pandillas en su país extorsionan a todo el mundo, incluidos los vendedores ambulantes.

Se unieron a la caravana porque la consideraron como una posibilidad de buscar una mejor vida: "Lo vimos como una oportunidad para salir de Honduras y buscar una vida mejor. Ya habíamos pensado en irnos, pero no teníamos los medios. Entonces, cuando nos enteramos de la caravana, dijimos: 'Esa es nuestra oportunidad'". Esta cita de Lorena evidencia que la caravana se convirtió en la única estrategia de movilidad para que ella y Víctor pudieran llevar a cabo su proyecto migratorio. Como ella misma lo comenta, "Al no haber dinero y como dijeron que era por $\mathrm{rai}^{8}$ (sic) y que teníamos que caminar, y caminar, no había, pues, y ya para venir para acá para nosotros no era posible, es tener plata para irse a otro país y nosotros no teníamos".

Víctor y Lorena viajaban con una sobrina de ella, quien a su vez traía a tres niños pequeños, entre ellos un bebé de 8 meses. Cuando llegaron al Estadio Palillo de la Ciudad de México, no tenían claro todavía si cruzarían la frontera hacia Estados Unidos. A pesar del largo camino que habían recorrido a pie y subiéndose a diferentes vehículos, seguían dispuestos y entusiastas de continuar hasta la frontera norte. Le pregunté a Víctor si sabía cuándo emprenderían el camino, rápidamente y con tono entusiasta me dijo: "No sabemos, pero si mañana nos dicen que nos vamos, estamos listos". En ese momento les esperaban aún más de 2,500 kilómetros para llegar a la frontera?

En la lluviosa tarde del jueves 29 de noviembre, volví a ver a Lorena y Víctor, esta vez en Tijuana ${ }^{10}$. Habían llegado a la frontera entre México y Estados Unidos. En un periodo de casi un mes habían recorrido 4,348 kilómetros desde San Pedro Sula, Honduras hasta Tijuana, México. En nuestro

\footnotetext{
${ }^{8}$ Del inglés ride (Méx. aventón).

${ }^{9}$ Trabajo de campo de la segunda autora en el Estadio Palillo, Ciudad de México, del 5 al 7 de noviembre 2018.

${ }^{10}$ Trabajo de campo de la segunda autora en Tijuana, 29 de noviembre al 7 de diciembre 2018.
} 
encuentro en la Ciudad de México se veían físicamente bien y su semblante reflejaba optimismo. Esta vez, en cambio, sus cuerpos mostraban los signos de un arduo y largo viaje, y su estado de ánimo denotaba incertidumbre y preocupación. Ambos se veían exhaustos y Lorena cojeaba de la pierna izquierda. Me comentó que se había caído al intentar subir a un camión que les había dado un aventón en su camino a Tijuana.

Lorena y Víctor llegaron a instalarse en tiendas de campańa, con otros caravaneros, en una colonia de clase media situada cerca de la playa. Ahí, además del frío y el viento de esos días de noviembre, sufrieron una violenta agresión de parte de los habitantes del lugar que se manifestaron contra los migrantes, los insultaron y les lanzaron piedras. La experiencia resultó ser, según su propio testimonio, la más dura que habían vivido desde su salida de San Pedro Sula.

Posteriormente, fueron trasladados con más de 6,000 personas a la Unidad Deportiva Benito Juárez. Después de dos semanas de acampar ahí, el lugar tuvo que cerrar por las fuertes lluvias y por las condiciones de insalubridad en que se encontraba hacinada la gente. Cerca de la mitad de quienes habían sido alojados en el centro deportivo fueron trasladados al albergue provisional El Barretal. Al igual que docenas de caravaneros, Lorena y Víctor no quisieron mudarse a este nuevo albergue debido a que se encontraba muy lejos del centro y lograron rentar un cuarto en uno de los hoteles aledańos al Benito Juárez. La sobrina de Lorena aceptó ser repatriada con sus hijos a Honduras, agotados, enfermos y vencidos por las condiciones en las que estaban viviendo en Tijuana y por la violencia antiinmigrante que habían padecido.

Una vez en la frontera, se iniciaba una nueva fase para los caravaneros. El muro entre México y Estados Unidos no solo significaba una barrera física infranqueable, sino que también representaba el fin de la movilización colectiva y el inicio de la búsqueda individual por la supervivencia. En el caso de Lorena y Víctor, ellos decidieron quedarse en Tijuana, tramitar sus tarjetas de visitantes por razones humanitarias, buscar trabajo y asentarse en esta ciudad. Así que cuando me despedí de ellos nuevamente, el 7 de diciembre, buscaban un cuarto para alquilar en una de las cuarterías de la Zona Centro de la ciudad. Sin embargo, la situación en la frontera se complicó, en parte por la falta de alternativas económicas y debido al constante arribo de centroamericanos 
y otros grupos de migrantes, entre ellos venezolanos, cubanos, haitianos y africanos.

Ante la dificultad de encontrar recursos, algunos hondureños que en los primeros meses del 2019 se encontraban todavía en Tijuana decidieron moverse a otras ciudades fronterizas con la esperanza de cruzar a los Estados Unidos, pues ya para ese momento había quedado evidente que en Tijuana resultaba imposible cruzar la frontera. A mi regreso a esta ciudad, en febrero, me informaron que Lorena y Víctor se habían ido a Reynosa, Tamaulipas. Como lo explicarían más adelante, un paisano de Honduras les había prometido que en esa ciudad tendrían un trabajo seguro y bien pagado, aunque eso no sucedió.

En mayo, durante una nueva estancia de trabajo de campo, la pareja acababa de regresar de Reynosa, donde habían pasado dos meses encerrados en un albergue para migrantes administrado por una iglesia cristiana. Según su testimonio, no les permitían salir del lugar sin ser acompañados por alguien del albergue. Hartos del encierro, terminaron por conseguir la ayuda económica para emprender, el 3 de mayo 2019, su viaje de 2,472 kilómetros de regreso a Tijuana ${ }^{11}$.

El trayecto entre Tijuana y Reynosa no solo es largo, sino que también es uno de los más peligrosos de México. Existe una alta presencia de crimen organizado en gran parte de esta ruta. Desafortunadamente, Lorena y Víctor fueron víctimas de un robo en el autobús en el que viajaban. En el momento en que los volví a ver, esta vez en compañía de la primera autora, tenían un par de días de haber llegado a Tijuana. Ambos se veían profundamente afectados por esta terrible experiencia. Sin embargo, Lorena era visiblemente la más afectada, su tono de voz era frágil, el llanto se hizo presente durante nuestro encuentro, y su lenguaje corporal manifestaba una fuerte vulnerabilidad. Los dos se veían afectados no solamente por el incidente de violencia del que fueron víctimas, sino sobre todo por la precariedad en la que se encontraban a su regreso a Tijuana. Les preguntamos si, ante tal situación, no pensaban en regresar a Honduras, a lo que rápidamente y con plena convicción nos contestaron, "no, no regresaríamos a Honduras, aquí estamos mejor."

En agosto 2019, Lorena y Víctor seguían viviendo en una de las cuarterías de la zona centro de la ciudad. Se trata de un inmueble con cerca de 18 cuartos

\footnotetext{
${ }^{11}$ Trabajo de campo, mayo 2019.
} 
ocupados por haitianos, centroamericanos y tijuanenses, en donde entre todos comparten un par de regaderas y un par de baños. Ambos trabajan de conserjes en una escuela secundaria de la zona. Ya tienen un pequeño refrigerador en su cuarto y lograron conseguir una mejor cama de la que tenían en nuestro último encuentro. Sus planes ahora son seguir trabajando, poner un pequeño negocio, ya sea de comida o ropa usada y, sobre todo, quieren comprar un pequeño terreno donde poder vivir.

\section{Douglas}

El 6 de mayo de 2019 entrevistamos a Douglas, migrante hondureño de 36 años. A diferencia de Lorena y Víctor, Douglas buscaba llegar a la frontera para pedir asilo en Estados Unidos. Él estaba esperando también cualquier oportunidad para huir, pero por razones muy diferentes: su trabajo como organizador comunitario en Tegucigalpa le trajo problemas con las llamadas maras, ya que trabajaba con jóvenes en situación de calle. Esto lo llevó a ser víctima de una brutal agresión por parte de los pandilleros. Ante esta situación y para evitar una muerte segura en caso de que lo volvieran a encontrar sus agresores, había decidido huir. Sin embargo, no contaba con los recursos económicos para viajar hacia el norte, así que al escuchar sobre la primera caravana la vio como una oportunidad.

Al ver a través de medios de comunicación que esta caravana había logrado cruzar a México, viajó hasta Tecún Umán y cruzó por su cuenta la frontera. Sin embargo, en la ciudad de Huixtla (Chiapas), antes de alcanzar la primera caravana, fue detenido por agentes de migración y deportado a Honduras. Al día siguiente, reemprendió inmediatamente el camino hacia Guatemala y la frontera con México. Al llegar, se encontró ahora con la segunda caravana, que había salido de Honduras el 20 de octubre, es decir justo cuando la primera se internaba en México. A diferencia de Víctor y Lorena, que siguieron los pasos de la caravana sin participar en la toma de decisiones, Douglas tuvo un rol de liderazgo a lo largo del camino que le permitió tejer redes con múltiples actores sociales, políticos y culturales.

Una vez en Tijuana, junto con un grupo de voluntarios y diferentes organizaciones locales, organizó un concierto cuyo propósito era "restaurar la mala imagen de la caravana y que sepan que los hondureños y centroamericanos traemos una riqueza, traemos sueños que queremos cumplir y que sabemos 
muy bien que podemos brindarle algo a Tijuana por todo el tiempo que nos ha albergado y lo que ha hecho por nosotros" (Entrevista con Douglas, 2019). El deseo de Douglas por mejorar las condiciones de los migrantes lo ha llevado, junto con otros dos hondureños, a emprender el proyecto de construir un albergue, Casa Hogar el Puente. Dicho albergue busca ser "un lugar destinado para alojar a mujeres migrantes y sus niños que sean solicitantes de asilo en Estados Unidos y que hayan sido retornados a Tijuana bajo el Programa de Protección al Migrante (MPP, por sus siglas en inglés)" (Página de Facebook de Douglas Oviedo).

Douglas fue parte de los primeros migrantes centroamericanos que fueron retornados a Tijuana bajo el acuerdo del $\mathrm{MPP}^{12}$. A partir de su retorno, la organización American Civil Liberties Union (ACLU) asumió su defensa y le proporcionó la ayuda de dos abogadas. El día que entrevistamos a Douglas había regresado de su segunda cita en la corte de migración.

A pesar de que los tres, Lorena, Víctor y Douglas, vieron las caravanas como una estrategia de movilidad, los dos primeros no tenían un plan una vez que lograran llegar a la frontera. Su idea era llegar "hasta donde los llevara la caravana”. Douglas, en cambio, fue observando desde el inicio los avances de la primera caravana y cuando vio que lograba cruzar la frontera entre Guatemala y México, tomó la decisión de alcanzarla. En su caminata con la segunda caravana, fue orientando la movilización colectiva para lograr el propósito de llegar a la frontera entre Tijuana y San Diego. Mientras que Víctor y Lorena se encuentran en una precariedad e incertidumbre legal, pues al vencer sus TVRH podrían perder su condición de estancia regular en México, en septiembre de 2019, Douglas obtuvo el asilo en Estados Unidos. Como dice Douglas, "la caravana fue algo que marcó mi vida. No sé para los demás migrantes. Bueno, para todos los migrantes que vinimos en la caravana esto marcó nuestra vida”.

\section{Conclusiones}

Las caravanas de 2018 pusieron en manifiesto la importancia numérica de la migración centroamericana que cruza México tratando de llegar a Estados ${ }^{12}$ Se trata de un acuerdo mediante el cual solicitantes de asilo en Estados Unidos, que entran por su frontera sur, pueden ser devueltos a las ciudades de la frontera norte de México para que esperen ahí todo su proceso de asilo en alguna corte de inmigración estadounidense. Estos procesos pueden durar varios meses y hasta más de un año. Cuando llega su cita en la corte, los solicitantes de asilo se presentan en la garita y los recogen las autoridades de ese país para conducirlos ante el juez. Después, son nuevamente retornados a México para esperar la resolución. 
Unidos. Por años, los migrantes centroamericanos han cruzado el país en forma de goteo, es decir en pequeños grupos y de manera casi invisible, para evitar ser presa de las redes criminales o de las políticas de detención y deportación.

Como estrategia de movilidad, la caravana representó la dualidad entre la visibilidad que daba a los miles de centroamericanos que cruzaban territorio mexicano, y la invisibilidad de estos migrantes a medida que se dispersaban y una vez que quedaron varados en la frontera entre Estados Unidos y México. A lo largo del camino y en algunos puntos de descanso, los migrantes iban acompańados por organizaciones de la sociedad civil, por organismos públicos de derechos humanos e incluso por cuerpos de seguridad como la propia policía federal. Viajaban así por el territorio mexicano de una manera relativamente segura y económicamente accesible. Sin embargo, a medida que avanzaban hacia el norte, continuar la ruta a pie en un solo contingente se volvió imposible; por falta de recursos, las organizaciones que acompañaban a los caravaneros no pudieron contratar un número suficiente de autobuses para continuar en grupo hasta la frontera norte. Al dispersarse, los migrantes fueron sujetos a abusos e incluso a violaciones muy graves a sus derechos humanos. No sólo varios sufrieron asaltos y robos en el camino, sino incluso secuestros y desapariciones, como lo narraron varios de los entrevistados.

La colectividad desapareció poco después de que los caravaneros arribaran a Tijuana y a otras ciudades fronterizas. En ese momento tuvieron que salir en busca de su propia supervivencia, lo cual dejó a la gran mayoría en una posición altamente vulnerable. En estas ciudades, tuvieron que confrontar por su cuenta los abusos de las policías municipales y de las autoridades, la falta de alternativas económicas, los ataques xenófobos y el enorme dispositivo de seguridad fronteriza del gobierno estadounidense.

Las caravanas evidenciaron la negación del derecho a la movilidad para la mayoría de la población que emigra o huye de sus lugares de origen. La movilidad es actualmente una suerte de privilegio de las elites políticas, económicas y científicas, mientras que las clases trabajadoras y los sectores excluidos o marginales que salen de sus lugares de origen o de residencia habitual para sobrevivir, se ven obligados a tomar caminos y medios clandestinos. Los destinos tradicionales se vuelven cada vez más elusivos a medida que los Estados llamados "de tránsito" erigen barreras, militarizan o securitizan las rutas migratorias. Así, la falta de alternativas para viajar por México con 
autorización, o con documentación migratoria, obliga a las personas a buscar estrategias cada vez más desesperadas para dirigirse hacia el norte. 


\section{Bibliografía citada}

Amnistía Internacional (AI), (2010) Victimas Invisibles. Migrantes en movimiento en México. Disponible en: https://www.amnesty.org/es/ documents/AMR41/014/2010/es/ (Consultado: 27 de agosto de 2019).

Animal Político, (1 de agosto 2019) "Policías locales asesinan a migrante en Saltillo" en Animal Politico. Disponible en: https://www. animalpolitico.com/2019/08/asesinan-migrante-saltillo-policiasagresion/ (Consultado: 27 de agosto de 2019).

Bibler Coutin, Susan, (2005) "Being En Route" en American Anthropologist. No. 107 (2), pp. 195-206.

Bustamante, Jorge, (2008) "Promotion and Protection of all Human Rights, Civil, Political, Economic Social and Cultural Rights, Including the Right to Development" en Report of the Special Rapporteur on the Human Rights of Migrants. Addendum (Mission to Mexico). Geneva: Human Rights Council, Eleventh Session, Agenda item 3, pp. 9 -15. COFAMIPRO, (2019) Inicio de Comité de Familiares de Migrantes Desaparecidos. Disponible en: https://migranteshonduras.org/elcomite-de-familiares-de-migrantes-desaparecidos-de-el-progresocofamipro/ (Consultado: 27 de agosto de 2019).

Colectivo de Observación y Monitoreo de Derechos Humanos en el Sureste Mexicano, (2019) Informe del monitoreo de derechos humanos del éxodo centroamericano en el sureste mexicano: Octubre 2018-Febrero 2019. Sistematización y redacción por Mary Garrapa. Disponible en: https://vocesmesoamericanas.org/wp-content/uploads/2019/05/ InformeExodo_Final-web.pdf (Consultado: 27 de agosto de 2019).

Comisión Nacional de los Derechos Humanos (CNDH), (2009) Informe Especial sobre los casos de secuestro en contra de migrantes. $\mathrm{CNDH}$. Disponible en: https://www.cndh.org.mx/sites/all/doc/Informes/ Especiales/2009_migra.pdf (Consultado: 27 de agosto de 2019).

Consejo Ciudadano del Instituto Nacional de Migración (CCINM), (2017) "Personas en detención migratoria en México." en Misión de monitoreo de las estaciones migratorias y estancias provisionales del Instituto Nacional de Migración. México: Consejo Ciudadano. 
De Alba, José Ignacio; Pernalete, Víctor y Daniela Pastrana, (2018) "La marcha de las carriolas" en En el camino, más allá de las vías. 11 de noviembre de 2018. Disponible en: https:/enelcamino.piedepagina. $\mathrm{mx} / \mathrm{la}$-marcha-de-las-carreolas/ (Consultado: 27 de agosto de 2019).

El Colef, (2018) La caravana de migrantes centroamericanos en Tijuana 2018: Diagnóstico y propuestas de acción. Tijuana, México: El Colegio de la Frontera Norte.

El Colef, (2019) La Caravana Centroamericana de Migrantes en Piedras Negras, Coahuila 2019. Diagnóstico y Propuestas de Acción [Informe]. El Colegio de la Frontera Norte.

El Colef, (2019) La Caravana de Migrantes Centroamericanos en Tijuana 2018-2019. Segunda Etapa [Informe]. Tijuana, México: El Colegio de la Frontera Norte.

Green, Linda, (2011) "The Nobodies: Neoliberalism, Violence and Migration" en Medical Anthropology. No. 30, pp.366-385.

Movimiento Migrante Mesoamericano, (2018) Caravana de Madres de Migrantes Desaparecidos - Catorce años de Lucha y Esperanza. Dsponible en: https://movimientomigrantemesoamericano.org/ category/caravana-de-madres-2018/

Oficina de Aduanas y Protección Fronterizas, (2019) Southwest Border Migration. Disponible en: https://www.cbp.gov/newsroom/stats/swborder-migration (Consultado: 27 de agosto de 2019.

París Pombo, María Dolores, (2017) Violencias y migraciones centroamericanas en México. Tijuana, México: El Colegio de la Frontera Norte.

París Pombo, María Dolores, (2019) "Las barreras migratorias en México y los términos de la colaboración con el gobierno estadounidense" en Calva, José Luis (coord.) Migración de mexicanos a Estados Unidos. Derechos humanos y desarrollo. México: Juan Pablos y Consejo Nacional de Universitarios.

Periodistas de Pie Org., (2014) Más de 72. Capítulo2. Disponible en: https:// masde72.periodistasdeapie.org.mx/capitulo2.html (Consultado: 27 de agosto de 2019).

Red de Documentación de las Organizaciones Defensoras de los Migrantes (REDODEM), (2018) El Estado Indolente. Recuento de la violencia en las rutas migratorias y perfiles de movilidad en México. Disponible 
en: https://fm4pasolibre.org/wp-content/uploads/2018/10/Informe_ REDODEM-ilovepdf-compressed.pdf (Consultado: 27 de agosto de 2019).

Rojas Wiesner, Martha y Maria DeVargas, (2019) "Strategic Invisibiility as Everyday Politics for a Life with Dignity: Guatemalan Women Migrants' Experiences of Insecurity at Mexico's Southern Border" en Menjívar, Cecilia; Ruiz, Marie y Emmanuel Ness Oxford Handbook of Migration Crises. Nueva York: Oxford University Press.

Varela,Amarela, (2012) “Del silencio salimos: la caravana de madres hondureñas en México. Un ejemplo de resistencia femenina al régimen global de fronteras" en Aquino, Alejandra; Varela, Amarela y Frédéric Decossé (coords.) Desafiando fronteras. Control de la movilidad y experiencias migratorias en el contexto capitalista. pp. 175-186. México: Edición Sur, Frontera Press.

Vogd, Wendy, (2013) "Crossing Mexico: Structural violence and the commodification of undocumented Central American migrants" en American Ethnologist. (40)4, pp.764-780.

Wolf, Sonja, (2014) "El ambicioso Programa Especial de Migración 20142018” en Animal Político. 7 de julio 2014. Disponible en: https:// www.animalpolitico.com/seguridad-180/programa-especial-demigracion-2014-2018-institucionalidad-y-recursos/ (Consultado: 27 de agosto de 2019). 